\title{
\begin{tabular}{l|l} 
pcori)? & PATIENT-CENTERED OUTCOMES RESEARCH INSTITUTE \\
RESEARCH SUMMARY
\end{tabular}
}

\section{Testing New Ways to Measure How Patients Rate Quality of Life}

Principal investigator

Bruce D. Rapkin, PhD
Organization

Albert Einstein College of Medicine

\section{What was the project about?}

Many research studies seek to learn how treatments affect patients' quality of life. Quality of life includes mood and energy. It also includes how people view their roles in their families or communities and whether they can perform those roles. Researchers use surveys to ask about patients' quality of life. But patients may answer the same question differently depending on their age, gender, or where they live. Some patients may think about their work roles while others may think about their families or social lives. How patients think about quality of life can affect what researchers learn about the effects of treatment.

In this study, the research team tested two surveys they created to measure differences in how patients think about their quality of life. The first, long survey had 74 questions, and the second, short survey had 23 questions.

\section{What did the research team do?}

The research team used statistical methods to compare how well the two surveys measured patients' reports of quality of life. The team compared patients' answers to questions in the two surveys. They also checked if the short survey worked as well as the long one.

The study included 110 patients treated for bladder cancer at three hospitals. Of these, 72 percent were white, 17 percent were black, and 16 percent were multiracial. The average age was 71 , and 70 percent were men. Patients filled out the two surveys at the start of the study and again three months later. They also filled out other surveys about mood and life experiences.
Patients, doctors, and patient advocates gave input on the study design.

\section{What were the results?}

The research team found that both surveys accurately measured how different patients think about their quality of life.

The research team found little overlap between the two surveys. The long survey captured more information than the short survey.

Both surveys predicted how quality of life responses change with changes in mood and life experiences. However, the long survey did better at these predictions than the short survey.

\section{What were the limits of the project?}

The study included a small number of patients with bladder cancer. Results may differ if the study included more patients or patients with other health problems. Also, the study lasted three months. Three months may not be enough time to study long-term changes in quality of life.

Future studies could test the surveys with patients in other locations or with other health problems.

\section{How can people use the results?}

Researchers can use these surveys when considering ways to look at how treatments affect patients' quality of life.

To learn more about this project, visit www.pcori.org/Rapkin274. 